\title{
Correlating Musculoskeletal Exercise with the Fitnessgram Test Standards
}

\author{
Liana Williams ${ }^{1}$, Kate Flowers ${ }^{1}$, John Mullen ${ }^{1}$ and Darrin Garcia ${ }^{1}$ \\ ${ }^{1}$ Santa Clara High School, Santa Clara, California, USA
}

\section{$\underline{\text { ABSTRACT }}$}

\section{Introduction}

Muscle strength and stamina are two important parts of a human's body capacity to run and do daily activities. There has been a strong positive correlation between physical activity and academic performance leading to health benefits. ${ }^{1}$ These benefits support the continuation of physical fitness into adulthood. According to Derrick Mears, a Clinical Associate Professor at the University of Arkansas, "The percentage of students enrolled in daily physical education has decreased 20 percent during the past twelve years with only $8 \%$ of elementary and $6 \%$ of middle and high schools providing programs that meet the recommendations for instructional time." ${ }^{2}$ With the lack of enrollment in physical education, it has caused childhood obesity rates to be one of America's many health concerns. Since the 1970s the number of adolescents affected by obesity has tripled. Between the ages of six to nineteen, it is likely that one in five children are obese. ${ }^{3}$

Along with choice of nutrition and physical activity, other factors such as genetics and metabolism can affect an increase in obesity. It is important to consider more immediate health risks such as high blood pressure (cardiovascular disease), type 2 diabetes, shortness of breath, gallstones, joint problems and musculoskeletal discomfort. With 13.7 million American children affected by obesity, these health risks put a significant sense of urgency on a child to seek the support necessary to change their habits. ${ }^{4}$

On the other hand, schools in California have adopted tests such as the Cooper Institute's Fitnessgram; created to increase the amount of time an individual participates in daily activities and to promote healthy lifelong habits. Section 60800 of the California Education Code (EC) requires each local educational agency to administer the tests in grades five, seven, and nine starting back in $1996 .{ }^{5}$ The Fitnessgram was designed to be the minimum requirement of physical exercise from elementary through to secondary school and was accepted by the State Board of Education. Although attempts have been made to address such health problems involving school-specific implications of fitness testing, there is no continuation of the Fitnessgram Tests for students beyond their ninthgrade year.

This new mixed method analysis presents implications of exploring the benefits of musculoskeletal fitness as it reduces the risk of injury and improves abdominal and back health. ${ }^{6}$ There is no current multivariate analysis study to illustrate whether students in their final year of high school have continued to meet the fitness standards.

${ }^{1}$ Fitness Assessment. (n.d.). Retrieved from https://fitnessgram.net/assessment/\#el-193fe973

${ }^{2}$ Kohl, H. W., \& Iii. (2013, October 30). Approaches to Physical Education in Schools. Retrieved from https://www.ncbi.nlm.nih.gov/books/NBK201493/

${ }^{3}$ Obesity. (2018, September 18). Retrieved from https://www.cdc.gov/healthyschools/obesity/index.htm

${ }^{4}$ Obesity. (2018, September 18). Retrieved from https://www.cdc.gov/healthyschools/obesity/index.htm

${ }^{5}$ Program Overview. (n.d.). Retrieved from https://www.cde.ca.gov/ta/tg/pf/pftprogram.asp

${ }^{6}$ Fitness Assessment. (n.d.). Retrieved from https://fitnessgram.net/assessment/ 


\section{Literature Review}

In 2007, the Texas Senate Bill 530 advised that as part of primary school (kindergarten to eighth grade) the students must take a physical assessment annually. However, no studies currently exist that use intervention, a means of experimentation, to improve scores from year to year ensuring that the students were meeting the healthy standards. With the intervention of the Texas Youth Fitness Study, the improved percentage for boys was a difference of 18 percent and girls was 15.5 percent. $^{7}$ In addition, the study correlates higher levels of fitness to consistent school attendance and more students passing the fitness test. The results of administering fitness exams and comparing students' scores to baseline standards led to Texas achieving better health.

The health benefits of adolescent physical activity are also supported by a study that emphasizes the effect of Belgian students transferring from elementary through to secondary school and their adaptation to lower levels of fitness. This longitudinal study concluded that out of a population of 736 students aged ten to thirteen, “...secondary schools seem more likely to foster strategies to promote PA (physical activity) during school hours than primary schools." ${ }^{8}$ According to the study, there needs to be policies established to encourage students from a young age to develop healthier behavior. The practice of physical activity at a young age has shown to increase activity in adulthood according to researcher Angela M. Craigie from the Centre for Public Health Nutrition. ${ }^{9}$ The trend in promoting lifelong healthy habits begins with adolescents.

Negative health outcomes have also been associated with the trend of decreasing involvement in physical activity as students transition from elementary to secondary school. ${ }^{10}$ Dr. Britton from Dublin City University in Evaluating a Conceptual Model of Physical Activity Engagement across the Transition from Primary to Secondary Schools, concluded that health related fitness rather than physical competence is the strongest mediator in determining the short-term effects on implementing physical assessments. Furthermore, information on differences within the model are a result based on gender and proximity. The study used a quantitative approach by incorporating exercises from the Fitnessgram test. Contrary to the previous study, this source provides information about the trend of staying physically active as the adolescents grow older.

It is commonly assumed that pull-ups are difficult muscular strength and endurance exercise compared to push-ups. However, another possible alternative isotonic ${ }^{11}$ test would be the modified pull-up. The benefits of testing the alternative is common in women and children, and it offloads one-third of the original body weight of each participant. ${ }^{12}$ In addition, since the sources focus on the entire body and not just a particular section like the upper body (arms and shoulders), there could be too many variables to measure which can have a massive impact on the student that wants to develop more muscular strength.

${ }^{7}$ Murray, T. D., Eldridge, J., Silvius, P., Silvius, E., \& Squires, W. G. (2012, January 15). FITNESSGRAM® Friday: A Middle School Physical Activity and Fitness Intervention. Retrieved from https://www.ncbi.nlm.nih.gov/pmc/articles/PMC4738980/

${ }^{8}$ De Meester, F., Van Dyck, D., De Bourdeaudhuij, I., Deforche, B., \& Cardon, G. (2014, March 19). Changes in physical activity during the transition from primary to secondary school in Belgian children: what is the role of the school environment? Retrieved from https://www.ncbi.nlm.nih.gov/pmc/articles/PMC3995550/\#!po=7.25806

${ }^{9}$ Craigie, A. M., Lake, A. A., Kelly, S. A., Adamson, A. J., \& Mathers, J. C. (2011, November). Tracking of obesity-related behaviours from childhood to adulthood: A systematic review. Retrieved from https://www.ncbi.nlm.nih.gov/pubmed/21920682

${ }^{10}$ Britton. (2019, November 1). Evaluating a conceptual model of physical activity engagement across the transition from primary to secondary school. Retrieved from http://doras.dcu.ie/23748/

${ }^{11}$ In a muscle action isotonic means taking place with normal contraction.

${ }^{12}$ Modified Pull-Up Test. (n.d.). Retrieved from https://shapeamerica.tandfonline.com/doi/abs/10.1080/10671315.1978.10615508?journalCode=urqe18\#.XiIgcujYrn G 
The muscular strength, endurance and flexibility fitness area in the Fitnessgram test help determine health status of all muscles and bones. In fact, balanced healthy system training affects muscles to strengthen over a period of time. Also, flexibility is important because it can reduce potential limitations in the transition from childhood to adulthood such as chronic lower back pain. ${ }^{13}$

In addition to the experiment conducted, study researchers Todd Sherman and J.P. Barfield, tested the reliability of the Fitnessgram test compared to other upper-body tests. The test focuses on the modified pull-up and the 90-degree push-up. Students in grades three to six had results similar to that of the Fitnessgram's healthy fitness zone standards. ${ }^{14}$ This must be noted since the correlation between the predetermined statistics of the Fitnessgram test correlate with that of the individual tested.

I will be conducting a study that will address the healthy fitness scores (determined by the Fitnessgram test) of high school seniors from a suburban California high school. The study will attempt to bridge the gap between Fitnessgram testing in California beyond the current grade level (ninth grade). In addition, the study will specifically target muscular upper body exercises to the projected standards of students between the ages of seventeen to eighteen.

\section{Methodology}

The method of my study addresses this question: to what extent does musculoskeletal exercises of the Fitnessgram test determine long-term upper body strength? The test aims to propose solutions to the obesity epidemic starting by targeting specific exercises in order to promote lifelong healthy habits.

The suburban California high school that will be observed does not require students to be tested on the Fitnessgram beyond the ninth grade. I hypothesize that without the requirement to take the Fitnessgram test, high school seniors will have lower mean scores compared to the baseline standards for adolescents older than seventeen as well as the participants self-reported estimates.

Students chosen for the study met the following inclusion criteria of being older than sixteen and a senior from the same suburban high school in California. The students were tested on the same four musculoskeletal exercises: the shoulder stretch, trunk lift, curl-up, and modified pull-ups.

This report uses the objective criteria used in the Fitnessgram test to examine high school seniors on their muscular strength, endurance, and flexibility. To obtain participants, one local high school in California with a population of 463 seniors were notified. Every senior from the high school received an email about the opportunity to complete a fitness test for compensation of a community service hour. When the students agreed to participate in the study, they were given a parental consent form, informed consent form, and online consent form (used for the questionnaire). These consent forms can be found in Appendix 1-3. A convenience sample of twenty-one students participated.

The explanatory sequential design used includes an analysis of a pre-test questionnaire, where the subjects answer questions about their typical exercise routine and their estimates of how many repetitions of each exercise the participant could complete. The qualitative survey which was designed using Google Forms was used to establish a standard range of self-reported responses for each exercise. The qualitative survey also included the use of short response and multiple-choice questions in an effort to identify whether the participant has met the inclusion

${ }^{13}$ Program Overview. (n.d.). Retrieved from https://www.cde.ca.gov/ta/tg/pf/pftprogram.asp

${ }^{14}$ Sherman, T., \& Barfield, J. P. (2006, December). Equivalence Reliability Among Upper-Body Tests of Muscular ... Retrieved from

https://www.researchgate.net/profile/Jp_Barfield/publication/233306380_Equivalence_reliability_among_the_FITN ESSGRAMR_upper-

body_tests_of_muscular_strength_and_endurance/links/5db1959ea6fdccc99d939f10/Equivalence-reliability-amongthe-FITNESSGRAMR-upper-body-tests-of-muscular-strength-and-endurance.pdf 
criteria. Qualitative data was chosen because an overview of self-reported scores could aid in drawing comparisons between the hours of physical activity the student participates in as well as comparison to the baseline standards. From those responses, I will, in person ask the students which date (that was pre-determined by myself) and what time slot the participant will be available for. Prior to participation all three consent forms will be obtained from each subject. Testing will take place at a physical therapy clinic in a suburb of California (where an additional consent form is needed to use the facility) and at a local high school weight room. Following the collection of qualitative data (from the survey), subjects will then see a demonstration of each exercise and have the option of trying the exercise before partaking in it. The quantitative data was used as a numerical comparison to the standards of the Fitnessgram test to observe whether or not the students were meeting the standard. Simply examining both factors, I was able to draw comparisons between self-reported responses and scores from each exercise. I used the Physical Fitness Test Reference Guide to demonstrate what is required of each exercise to meet the standard.

The first test will be the shoulder stretch. The shoulder stretch is an alternative to the sit and reach test that illustrates the importance of flexibility in all areas of the body. Upper body flexibility benefits those that engage in more rigorous physical activity. This test did not require any extra equipment. The participants were instructed to begin the shoulder test with the left shoulder by placing their left hand over your left shoulder on their back. Meanwhile the students placed their right hand up on their back with their palm facing up as if to touch left hand fingertips. This process was repeated but, in reverse order for the right hand. I will use the Fitnessgram test to see whether the participant passed on both arms.

Secondly, the trunk lift predicts a major disability discomfort in the U.S. for the first time, and recurrent back pain. The students were first instructed to complete a warmup where they would lean down hands behind back and lift their chin up as high as they could. Students lie on the mat face down toes pointed and hands under their thighs. On the floor a marker is placed according to the size of the student. By keeping the focus on a piece of tape on the floor while lifting the trunk, the participant should be better able to keep their head in the correct position. I will then use a ruler to measure the distance from the mat to the top of the participant's chin. During the trunk lift student with a maximum height of 30 centimeters lifts the upper body in a slow manner off the floor. The students' heads should be straight in alignment with the side. Slowly have subjects return to starting position two trials are allowed with high scores recorded. The maximum is 30 centimeters in whole numbers rounded down. If it exceeds the Healthy Fitness Zone, continue regular physical activity otherwise another exercise should be suggested. I will then have the participant take a two-minute break before the curl-up test.

Thirdly, the curl-up test, was designed to have students follow a 20 curl-up per minute cadence. A 11.4centimeter measuring strip (tape) was placed on a mat under the knees of the participant with the front edge indicating the start position and the width of the tape being how far the participant must slide their fingertips across. Abdominal strength and stamina are essential for promoting good posture and correct alignment. The objective of this test was to complete as many curl-ups as possible with the maximum value at 75 at the specified pace ( 1 curl-up every 3 seconds). ${ }^{15}$ On the mat the student lies on their back knees bent to form the shape of an acute triangle with feet flat and palms facing down at the participants side on the mat. Slowly moving, students curl-up sliding fingers across the mat on a measuring strip, and curl-down until the head touches the mat.

Finally, the modified pull up is used to measure strength and endurance in the upper body. It is important in maintaining functioning health and good posture. This falls under the category of push-up and flexed-arm hang. The objective of the modified pull up is to complete as many as possible. The equipment used for the modified pull up is the pull up stand, elastic band, paper, and mat. The warm-up to prepare to improve both performance and reduce injury is running in place for at least 10 seconds. First lie on your back with shoulders right underneath the bar that is set 1 to 2 inches from students' reach. There is an elastic band that is connected to the middle of the bar 7 to 8 inches long. The student is instructed to hold the bar with an overhand grip. The student must get down in position with arm and legs straight and hips off the floor and only heals in contact with the floor the student must

${ }^{15}$ pdf. (n.d.). 
demonstrate a continuous rhythmic movement. The student is permitted to form brakes and the stop (rest and refrain from doing the exercise) after the second one. Any one of these four things can be a form break: chin not over the elastic band, does not maintain a straight position of the body with only heels in contact with the floor, arms not fully extended in downward position, and does not maintain a rhythmic pace.

Once the quantitative data is collected, I will explain and interpret the data and compare it with the standards of the Fitnessgram test. The entire study in full should take no longer than one hour to complete, including filling forms out, demonstrations, and testing.

\section{Randomized Block Design}

In order to conduct my experiment, I chose to use a statistical block design, where I divided participants into subgroups (by gender) to limit the differences between the blocks. Within each group the participants are assigned the same four treatments (in this case shoulder stretch, trunk-lift, curl-up, and modified pull-up). The participants within the first block (males) were instructed to take the four exercises on the Fitnessgram test at one of the testing locations. The second block (females) completed the same four exercises in the same order and location as block one. This design negates potential confounding by better treatment estimates effects and explicit controls for gender. For this design, eleven boys age seventeen and older from California chose to take the fitness test at their local high school. Additionally, ten girls with the same criteria chose to participate and receive treatment (the four exercises). This design ensures there is an equal proportion of males and females in each treatment condition. This block design therefore eliminates gender as a potential source of variability and as a potential confounding variable.

Table 1 is a two-way table that shows the two subjects that will be evaluated: seniors and freshman. The freshmen have question marks because the data will be compared to the overall California consensus in Fitnessgram testing. Figure 1 is the experimental design method (illustrated in a chart) used to obtain participants and assign them to a treatment (exercise). These figures were designed to illustrate the process of organizing the experimental procedure.

Table 1: Treatment Groups

\begin{tabular}{|c|c|}
\hline Gender & Treatment \\
\hline Male & 11 \\
\hline Female & 10 \\
\hline
\end{tabular}

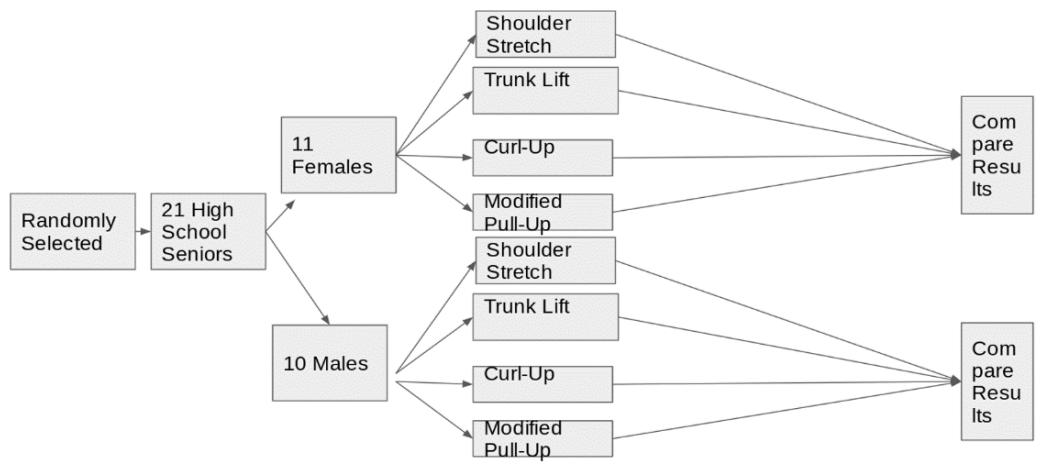

Figure 1: Experimental Design 


\section{Results}

As stated in the methodology section, constraints of the randomized block design led to students being tested on different days. Information about the materials needed to complete the experiment can be found in Appendix 5. Figure 2 displays the materials used to measure.

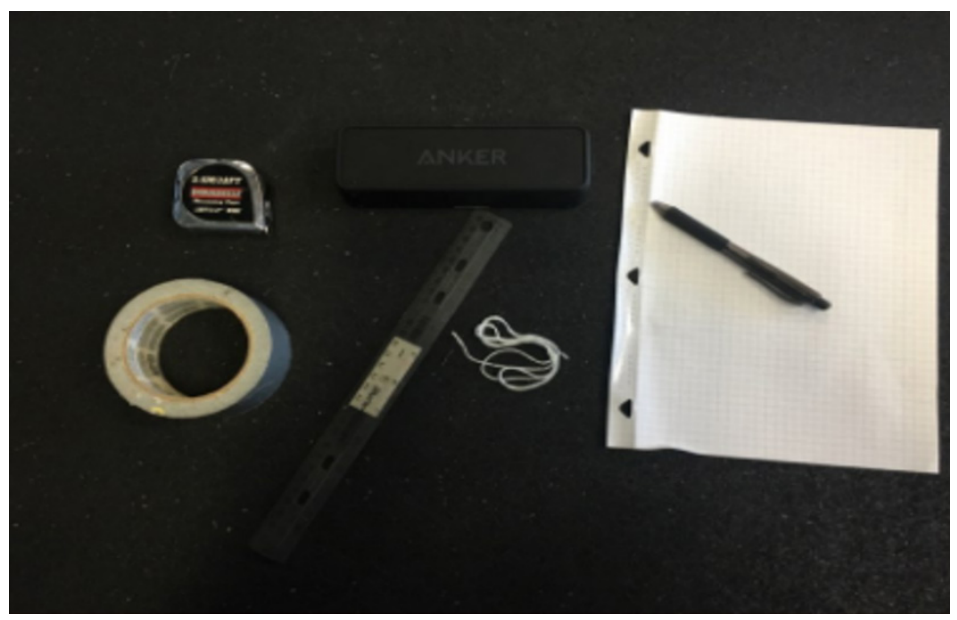

Figure 2: Measuring Materials

The first results presented a convenience sample of 25 members in the senior class at a high school in California. Of the twenty-five students asked to participate twenty-one responded and completed the experiment. Two males and two females communicated verbally that they could not complete the activity at any of the four testing dates. Samples of emails sent to the two mentors to schedule dates will be found in Appendix 4. Of those who responded, 11 were males aged 17-18 and 10 were females aged 17-18. Testing each participant took roughly twenty minutes: 5 minutes to complete the pre-test survey, one minute between each exercise to explain (what muscle groups it works on, why the muscles in that area are important, and what are errors that one can make on each test) 4 minutes and 30 seconds for curl-ups, 2 minutes for the shoulder stretch (including both sides), 3 minutes modified pull-ups. The students were tested in the same manner starting with the shoulder stretch, followed by the trunk lift, curl-up, and modified pull-up. There were two locations and the materials for both studies were the same.

Unfortunately, the biggest barrier in understanding youth fitness results is detecting future health outcomes. It has been difficult to determine the main causes of obesity and other health related issues but, is compensated in the short run.

\section{Pre-Test Findings}

This brief questionnaire will ask a series of questions in order for me to make comparisons at the end of the study with the entire sample population. All information was kept confidential and coded. The participants were informed that there are no wrong answers and that each question should be answered to the best of their ability. Appendix 7 includes the questions asked in the study.

This pre-test survey was created in order to assess whether or not the students from the high school met the inclusion criteria. One of the most important factors taken into consideration was the overall health of all participants prior to completing the test. The survey asked a series of questions: the participant's name (which is kept anonymous for confidentiality purposes), gender (female, male, or non-binary), whether or not the student has been enrolled in the particular school district in California that uses the Fitnessgram test, how many hours a week 
they engage in physical activity, and their expectations of how many of each exercise they would be able to accomplish.

$71.4 \%$ of the students were 17 years old at completion of the test and $28.6 \%$ of students were 18 at the time of participation. 17 out of the 21 students reported being a part of the particular school district since the fifth grade therefore, showing familiarity with the expectations of the Fitnessgram test. One student had never taken the Fitnessgram test before the seventh grade. The other students reported to have taken the test in seventh and ninth grade with sixteen students performing the test in fifth grade. The data from the exercise bar chart is skewed to the right with a peak at two hours a week meaning $23.8 \%$ (or 5 students) work out roughly two hours a week. The students were also asked a series of questions relating to the quantity and quality of each exercise one will complete. These results were originally taken to compare with the results the students had but will be used in the analysis process as almost all students reported lower scores than what they received on the test. The amount of physical exercise was taken into consideration in limitations to the study design.

How many curl-ups do you expect to do before making two errors in technique? 21 responses

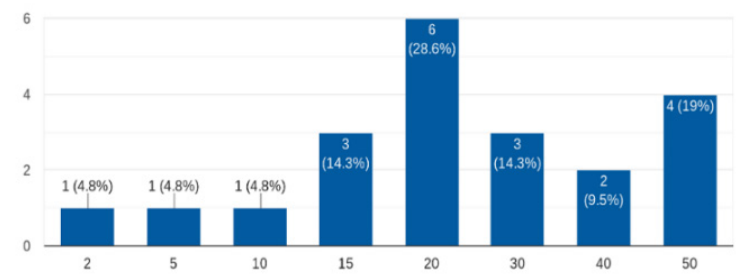$$
\text { How high do you think you can lift your chin laying on the ground? (Must be a whole number) }
$$$$
\text { inches }
$$$$
21 \text { responses }
$$

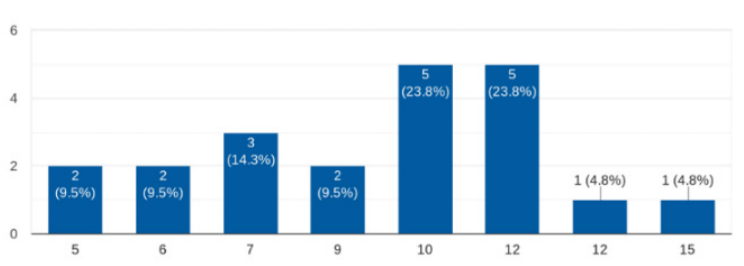

During the week how many hours do you engage in a physical activity? Ex: sports, gym, walking etc. 21 responses
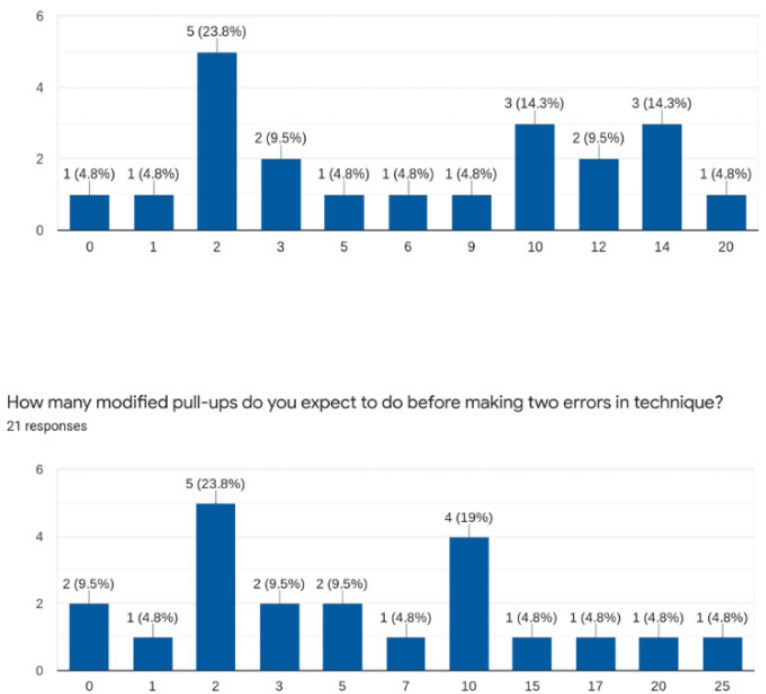

In what grades did you take the Fitnessgram test? (Check all that apply) 21 responses

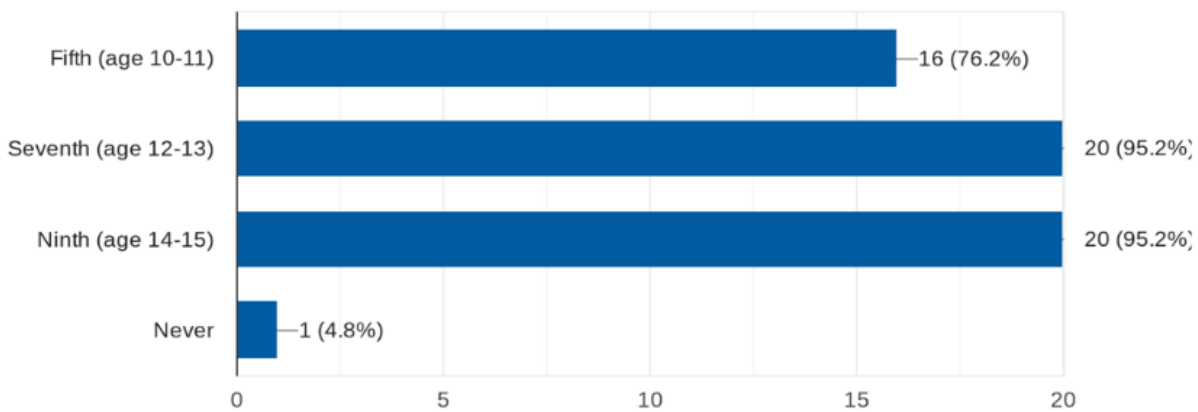

Figure 3a-c: Hours of Exercise 


\section{Data Table}

In order to keep the participant information confidential, both genders were assigned a number that corresponded to the order the students chose to participate. Appendix 8 displays two data tables separated by gender (males on the left and females on the right) comparing the results of individuals sixteen and older based on the California Fitnessgram average scores for meeting the healthy fitness zone. ${ }^{16}$ Figures 5-10 illustrate the data in forms of pie charts comparing individuals within their grouping based on gender. The symbol (M) stands for male and (F) stands for female. Since the shoulder stretch uses objective criteria and is qualitative the student was evaluated on whether they could perform the exercise correctly $(\mathrm{Y})$ or failed to meet the healthy fitness standard (touching fingertips) which is noted as $(\mathrm{N})$. From the data collected in the shoulder stretch all male and female students passed the right shoulder test. The male students had a lower passing rate than the female students on the left shoulder test $80 \%$ to $90 \%$.

The trunk lift was measured in centimeters (notated as $\mathrm{cm}$ ) where the students were told to stop the exercise when they surpassed 30 centimeters (as this was the marking point for healthy fitness standards). The mean value or central tendency for males participating in the trunk lift which was $27.24 \mathrm{~cm}$ (where any value that exceeded $30 \mathrm{~cm}$ was recorded as $30 \mathrm{~cm}$ in the calculations). There was a standard deviation of 3.15 where students scored either above or below the mean. The smallest value (minimum notated as $\min$ ) was at $20.32 \mathrm{~cm}$, the middle value of the dataset (median notated as med) was $28.6 \mathrm{~cm}$ and the maximum value (notated as max) was at $30 \mathrm{~cm}$. Results of the female participants for the trunk lift had a mean of $28.3 \mathrm{~cm}$, standard deviation of 2.74, min: 21.59, Med:29.9, Max: 30. The third test was the curl-up test that counted the number of repetitions each student could complete. Males had a mean of 56.3 with a standard deviation of $17.7, \min : 29$, med:60, and a maximum of 75 . While females had a mean of 34.6, standard deviation of 16.2, min:17, Med:30.5, and maximum of 75. Finally, the modified pull-up for males the mean was 16.1, standard deviation of 6.6, min:10, med:15, max:33. Whereas the females had a mean of 4.9, standard deviation of 3.5, min:1, med:4.5, and max:11. These results were then compared to the Fitnessgram scores. Table 2 and 3 includes a key that is used to define notation of the data table and pie chart.

Table 2: Key \& Male Subjects.

A1(M) corresponds to the first male subject tested; $\mathbf{Y}$ suggests "yes" passing score for the test; $\mathbf{N}$ suggests "no" not passing score for the test; Exceeded $30 \mathbf{~ c m}$ met the Fitnessgram standard.

\section{Males}

\begin{tabular}{|c|c|c|c|c|c|}
\hline Male Subjects & $\begin{array}{c}\text { Shoulder } \\
\text { Stretch (Left) }\end{array}$ & $\begin{array}{c}\text { Shoulder } \\
\text { Stretch (Right) }\end{array}$ & Trunk Lift & Cur-Up & $\begin{array}{c}\text { Modified Pull- } \\
\text { Up }\end{array}$ \\
\hline A1 (M) & Y & Y & Exceeded 30cm & 52 & 20 \\
\hline A2 (M) & Y & Y & $24.13 \mathrm{~cm}$ & 75 & 16 \\
\hline A3 (M) & N & Y & Exceeded 30cm & 55 & 10 \\
\hline A4 (M) & Y & Y & Exceeded 30cm & 74 & 17 \\
\hline A5(M) & Y & Y & Exceeded 30cm & 75 & 12 \\
\hline A6(M) & N & Y & $20.32 \mathrm{~cm}$ & 29 & 10 \\
\hline A7(M) & Y & Y & $27.94 \mathrm{~cm}$ & 32 & 15 \\
\hline A8(M) & Y & Y & $29.21 \mathrm{~cm}$ & 75 & 33 \\
\hline A9(M) & Y & Y & $25.4 \mathrm{~cm}$ & 60 & 22 \\
\hline A10(M) & Y & Y & $25.4 \mathrm{~cm}$ & 36 & 12 \\
\hline
\end{tabular}

${ }^{16}$ CEDR Systems, \& California Department of Education. (n.d.). California Physical Fitness Test (PFT). Retrieved from https://pftdata.org/resources.aspx 
Table 3: Key \& Female Subjects

A1(F) corresponds to the first female subject tested; $\mathbf{Y}$ suggests "yes" passing score for the test; $\mathbf{N}$ suggests "no" not passing score for the test; Exceeded $30 \mathrm{~cm}$ met the Fitnessgram standard.

Females

\begin{tabular}{|c|c|c|c|c|c|}
\hline $\begin{array}{c}\text { Female } \\
\text { Subjects }\end{array}$ & $\begin{array}{c}\text { Shoulder } \\
\text { Stretch (Left) }\end{array}$ & $\begin{array}{c}\text { Shoulder } \\
\text { Stretch (Right) }\end{array}$ & Trunk Lift & Cur-Up & $\begin{array}{c}\text { Modified Pull- } \\
\text { Up }\end{array}$ \\
\hline A1 (F) & Y & Y & Exceeded $30 \mathrm{~cm}$ & 31 & 1 \\
\hline A2 (F) & Y & Y & Exceeded $30 \mathrm{~cm}$ & 28 & 11 \\
\hline A3 (F) & Y & Y & $25.4 \mathrm{~cm}$ & 30 & 1 \\
\hline A4 (F) & Y & Y & Exceeded $30 \mathrm{~cm}$ & 38 & 3 \\
\hline A5 (F) & Y & Y & Exceeded $30 \mathrm{~cm}$ & 75 & 4 \\
\hline A6 (F) & N & Y & Exceeded $30 \mathrm{~cm}$ & 34 & 9 \\
\hline A7 (F) & Y & Y & $21.59 \mathrm{~cm}$ & 50 & 5 \\
\hline A8 (F) & Y & Y & $29.85 \mathrm{~cm}$ & 18 & 1 \\
\hline A9 (F) & Y & Y & $29.85 \mathrm{~cm}$ & 25 & 9 \\
\hline A10 (F) & Y & Y & $26.67 \mathrm{~cm}$ & 17 & 5 \\
\hline
\end{tabular}

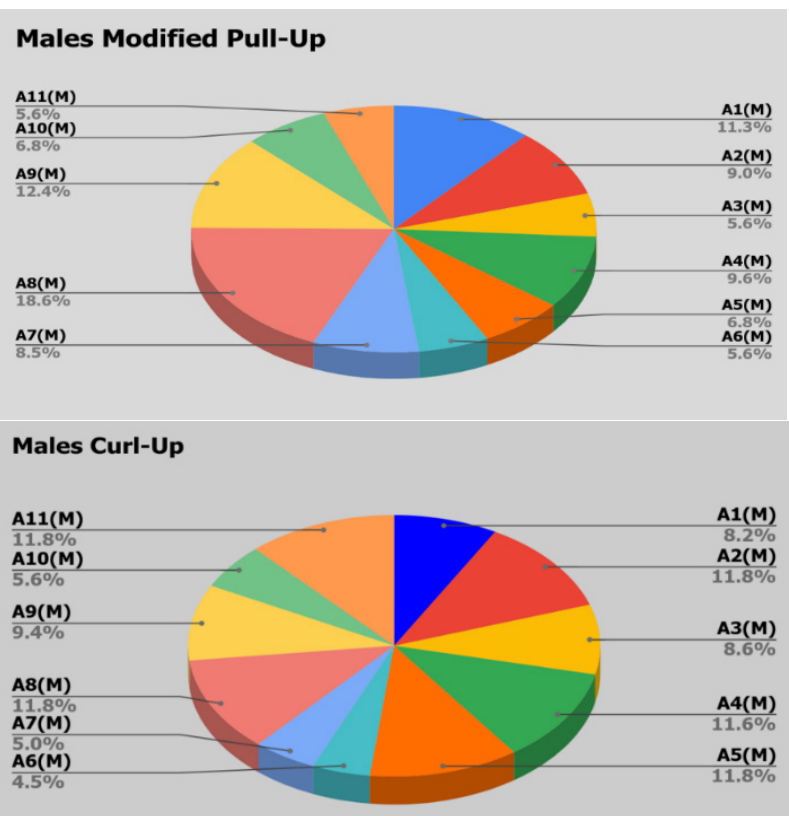

Female Shoulder Stretch LEFT

$\frac{N}{10.0 \%}$

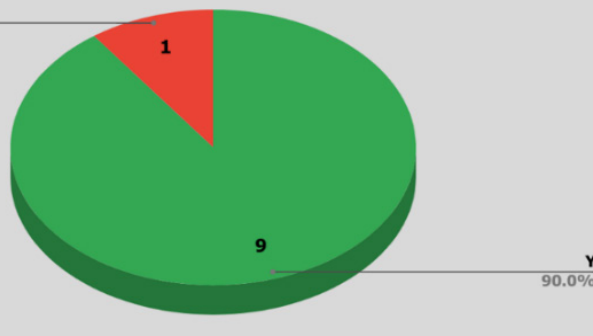

Females Modified Pull-Up

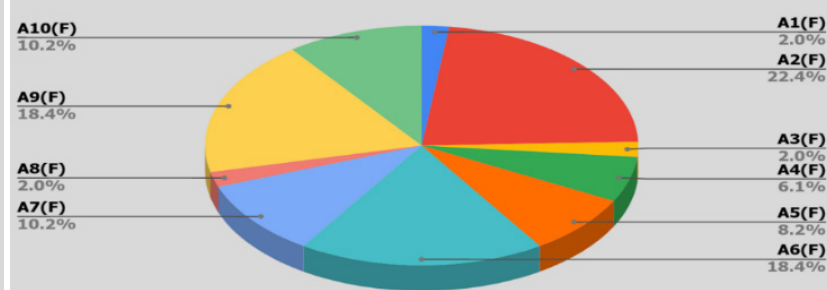

Females Curl-Up

A10(F)

$4.9 \%$
A9(F)

$\mathbf{A B ( F )}$

$A 7(F)$

$14.5 \%$

${ }_{9.8 \%}^{A 6(F)}$

Male Shoulder Stretch LEFT

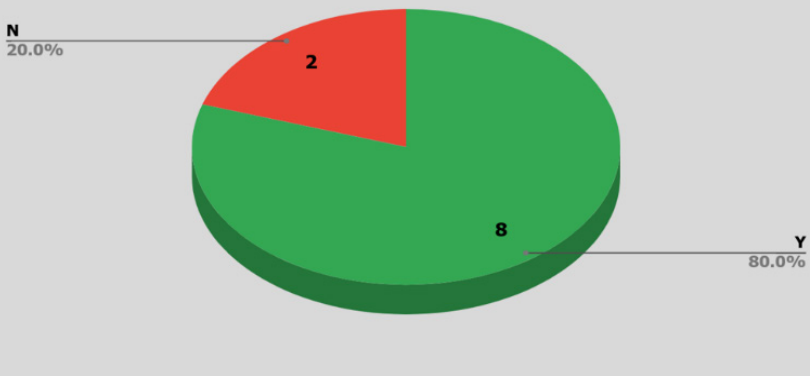

Figures 4-9: Pie Chart Summaries 


\section{Discussion}

The experiment involved examining the difference between groups with one or more variables observing the numerical differences in comparison to the Fitnessgram standards.

The five number summary was used to provide a statistical comparison of the results. The information regarding calculations for both male and female participants may be found in Appendix 6. The shoulder stretch was not included in the five number summary because to meet the Healthy Fitness Zone standards the participant had to be able to touch fingertips (which led to a yes or no answer). The mean was used to compare the averages of each of the values of the participants. The main focus of this analysis is to understand whether the subjects in my study met the healthy fitness criteria in order to conclude whether conducting a Fitnessgram test. The notation in the chart of Q1 and Q3 are the values that divide the data into quarters and are known as quartiles.

In order to determine outliers from the sample population the interquartile range was calculated. Therefore, any numerical result that lies outside of the range is not normal. Where the results for the males were curl-up: 22.5133.5, trunk lift: -18.5-36.9 cm, and modified pull-up: 5-35. As for the females curl-up: -5.5-57.5, trunk lift: -21.75$34.95 \mathrm{~cm}$, and modified pull-up: 20-21.

The data involved a convenience sample where it is only possible to draw cause and effect conclusions and results between the like people (similar genders) that participated in the study. Starting with the males from my study they had significantly higher mean scores than the Fitnessgram baseline standards of students aged sixteen and older. Within the sample population the females also had significantly higher means than the average from the females in California but, the results were fairly close in the modified pull-up test. For both males and females a higher mean and standard deviation indicates the data points are right-skewed and illustrate that the participants did significantly better than normal. In comparison to the pre-test results since the participants spent a significant amount of time dedicated to physical activity (keeping up with their healthy habits from previous years) it corresponds to the higher mean.

\section{Conclusion}

In response to the childhood obesity epidemic, schools should have a partial obligation in promoting healthy practices with physical activity and balanced meals. In order to prevent the risk of chronic diseases examples include high blood pressure, cholesterol and glucose has led to more research conducted on school-based health education and promotion of exercise. ${ }^{17}$ This research provides a synthesis of previous health guidelines as well as the resulting health conditions from lack of physical activity. From the research one can include that if the trend of obesity in adolescents continues to rise, immediate health risks can affect them well into adulthood.

To summarize, the data shows that students from a suburban high school exercising at least five hours a week produce higher mean averages for upper body exercises. The incentive is that the results of the study will be shared with the participant in addition to receiving community service hours. This conclusion negates the initial predictions made prior to performing the methodology, with additional detail, especially pertaining to the how long one is physically active and the exercises chosen. For the majority of the data, we can conclude that the study proved to not be successful as a majority of the participants met/exceeded the Fitnessgram standards even without physical activity being offered through school. The potential implications and limitations of this conclusion will be outlined in the following section. I hope, however, that the study's information can help inform participants about the benefits of musculoskeletal exercises to promote lifelong healthy habits.

${ }^{17}$ Division Of Adolescent And School Health, National Center For Chronic Disease Prevention And Health Promotion. (2011, September 16). School Health Guidelines to Promote Healthy Eating and Physical Activity. Retrieved from https://www.jstor.org/stable/24842389 


\section{Limitations}

When gathering subjects to participate in the study there was a non-response from the $10 \%$ of the schools population that were randomly selected. In order to gather participants (and gather information) flyers were posted on campus for students to contact the researcher in person on when to participate. Since a convenience response sample was taken instead of a random sample, I was not able to generalize the results of my study to the entire baseline standards as noted by the Fitnessgram test. However, this does not present a generalization of all high school students in California since we can only infer the results similar to another school. This is due to a bias from the convenience sample where students were not randomly selected in order to avoid non-response. I have been able to draw cause and effect conclusions that apply to people like those who took part in the experiment. Not all testing was done on the same day or same location as noted by the schedules but, the same equipment was used for each participant.

There are limitations to comparing the amount of students that participated in my study to the averages. Since the data was gathered from a convenience sample, there was an abundance of athletes that participated as seen by the self-reported hours of physical activity a week in Figure 3. There was also a lack of preparation for the students that were not actively involved in a Fitness class. This was compensated by having each student try out each exercise in order for them to try to match proper form and technique. Finally, more information such as each student's biometrics (height and weight) would allow for researchers to make more comparisons within the sample size and will be useful to examine in the future.

\section{Future Decisions}

Some experiments have investigated the influence of state requirements on young adults physical activity rates for physical education classes. For the minimal study, the findings were contradictory, and the effect of these experiments on the encouragement of physical exercise is challenging to truly determine. A large percentage of individuals met the criteria in the physical education region. These findings contrast with those previously stated in the literature review. If this experiment were to be replicated, then there should be more variation in the students involved in the study that may not be involved in a school or club sport to get a better representation of the data. It may be more beneficial to include an entire school district comparing the geography of a location with a different one. Finally, another alternative to the study if time permits would be to track the students physical fitness ability (the maximum repetitions on each exercise) to see how proper training affects health.

\section{Work Cited}

Britton. (2019, November 1). Evaluating a conceptual model of physical activity engagement across the transition from primary to secondary school. Retrieved from http://doras.dcu.ie/23748/

CEDR Systems, \& California Department of Education. (n.d.). California Physical Fitness Test (PFT). Retrieved from https://pftdata.org/resources.aspx

Craigie, A. M., Lake, A. A., Kelly, S. A., Adamson, A. J., \& Mathers, J. C. (2011, November). Tracking of obesityrelated behaviours from childhood to adulthood: A systematic review. Retrieved from https://www.ncbi.nlm.nih.gov/pubmed/21920682

De Meester, F., Van Dyck, D., De Bourdeaudhuij, I., Deforche, B., \& Cardon, G. (2014, March 19). Changes in physical activity during the transition from primary to secondary school in Belgian children: what is the role of the school environment? Retrieved from https://www.ncbi.nlm.nih.gov/pmc/articles/PMC3995550/\#!po=7.25806 
Division Of Adolescent And School Health, National Center For Chronic Disease Prevention And Health

Promotion. (2011, September 16). School Health Guidelines to Promote Healthy Eating and Physical

Activity. Retrieved from https://www.jstor.org/stable/24842389

Equivalence Reliability Among the FITNESSGRAM $®$ Upper-Body Tests of Muscular Strength and Endurance.

(n.d.). Retrieved from https://www.tandfonline.com/doi/abs/10.1207/s15327841mpee1004_2

Fitness Assessment. (n.d.). Retrieved from https://fitnessgram.net/assessment/\#el-193fe973

Kohl, H. W., S.), I. of M. (U., Cook, H. D., III, H. W. K., \& Cook, H. D. (2013). Educating the Student Body: Taking Physical Activity and Physical Education to School. National Academies Press.

Kohl, H. W., \& Iii. (2013, October 30). Approaches to Physical Education in Schools. Retrieved from https://www.ncbi.nlm.nih.gov/books/NBK201493/

Modified Pull-Up Test. (n.d.). Retrieved from https://shapeamerica.tandfonline.com/doi/abs/10.1080/10671315.1978.10615508?journalCode=urqe18\#.Xi IgcujYrnG

Murray, T. D., Eldridge, J., Silvius, P., Silvius, E., \& Squires, W. G. (2012, January 15). FITNESSGRAM® Friday: A Middle School Physical Activity and Fitness Intervention. Retrieved from https://www.ncbi.nlm.nih.gov/pmc/articles/PMC4738980/

Obesity. (2018, September 18). Retrieved from https://www.cdc.gov/healthyschools/obesity/index.htm

Program Overview. (n.d.). Retrieved from https://www.cde.ca.gov/ta/tg/pf/pftprogram.asp

pdf. (n.d.).

Sherman, T., \& Barfield, J. P. (2006, December). Equivalence Reliability Among Upper-Body Tests of Muscular ... Retrieved from https://www.researchgate.net/profile/Jp_Barfield/publication/233306380_Equivalence_reliability_among_t he_FITNESSGRAMR_upper-

body_tests_of_muscular_strength_and_endurance/links/5db1959ea6fdccc99d939f10/Equivalence-

reliability-among-the-FITNESSGRAMR-upper-body-tests-of-muscular-strength-and-endurance.pdf 